\title{
Comunicação interna: o colaborador nas pautas do jornal Grand News ${ }^{1}$
}

Vinícius Rodrigues M. Silva

Pontifícia Universidade Católica do Rio de Janeiro - PUC-Rio

Departamento de Comunicação Social - Bacharelado em Jornalismo

\section{RESUMO}

O presente artigo apresenta uma análise do conceito de cultura organizacional inserida como estratégia de uma companhia. O objeto desta análise será o jornal interno Grand News veiculado pela comunicação interna do hotel Grand Hyatt Rio de Janeiro. O objetivo será compreender a percepção dos colaboradores ao serem inseridos nas pautas do jornal e se eles se sentem integrados e co-participantes da cultura da empresa. Nesse contexto, é apresentada a estratégia global da Hyatt no contexto da marca Grand Hyatt e a sua presença na cidade do Rio de Janeiro. O que se propõe para realizar esta pesquisa será a análise do jornal interno e também a realização de entrevistas com os colaboradores do hotel, a fim de coletar informações que possam sugerir a percepção nas reportagens do jornal Grand News.

\section{PALAVRAS-CHAVE}

Cultural organizacional; Comunicação interna; House organ; Jornal interno.

\section{Introdução}

A rotina das organizações é definida por uma cultura organizacional que é estimulada por canais externos e internos. Dentro desse contexto, é possível conduzir o público por meio de signos que fazem parte da estratégia da empresa (MOTTA e VASCONCELOS, 2008). A cultura organizacional é um padrão de pressupostos básicos que regem ao comportamento dos indivíduos na organização (TOMEI, 2018).

Um destes importantes canais de transmissão da cultura organizacional é a comunicação interna, presente em muitas empresas como meio gerenciador e propagador do propósito e valores que são incorporados ao dia a dia do colaborador, tido como público interno da organização (KUNSCH, 2006).

\footnotetext{
1 Artigo derivado de monografia de graduação em Jornalismo, orientada pela professora Luciana Pereira e apresentada em julho de 2019.
} 
Meu interesse em pesquisar este tema se deu pela minha experiência como estagiário de Comunicação interna no hotel Grand Hyatt Rio de Janeiro. O hotel faz parte de uma rede americana que possui no portfólio diversos de marcas que compõem a organização.

Iniciei meu estágio na empresa no ano de 2017 e, dois anos depois, passei atuar como Assistente de Comunicação interna. Entre as minhas atribuições estiveram o planejamento anual de comunicação, a produção do material gráfico e textual dos canais de comunicação e também a produção dos eventos que envolvem os colaboradores do hotel. A partir desta experiência, pretendo com este artigo analisar a percepção do colaborador quando é inserido nas pautas do principal veículo de comunicação interna da companhia: o jornal Grand News.

Partindo desse pressuposto, será fundamental um aprofundamento nas estratégias de comunicação empresarial e entender de que maneira o house organ atua como veículo jornalístico facilitador dentro da organização (PALMERSTON, 2012). Dentro dos conceitos que englobam o jornalismo, também serão elucidados os conceitos de notícia, pauta e os critérios de noticiabilidade de um fato.

Aberto desde março de 2016, o hotel vem adaptando sua comunicação com base na estratégia definida pelo conselho corporativo global e também por meio da pesquisa de clima da organização. A empresa atua por meio de valores e de um propósito definidos pela companhia e que tem o objetivo de estimular o público interno de maneira global.

Neste trabalho, darei foco na forma como o colaborador é inserido na estratégia da empresa a fim de promover o sentimento de pertencimento e diálogo. Kunsch (2006) aponta a comunicação com o objetivo de estimular o diálogo entre os colaboradores em diferentes níveis hierárquicos e assim torná-la eficaz ao valorizar seus membros como cidadãos pertencentes a organização.

Para análise desta estratégia também foram entrevistados colaboradores que estão na empresa desde a abertura para entendermos a partir do discurso deles de que maneira foi percebido o direcionamento das matérias no jornal interno. Para obter os dados de análise foi utilizado o método de Entrevista em Profundidade (DUARTE e BARROS, 2012).

A entrevista em profundidade é um recurso metodológico que busca, com base em teorias e pressupostos definidos pelo investigador, recolher respostas a partir da experiência subjetiva de uma fonte, selecionada por deter informações que se deseja conhecer. (DUARTE e BARROS, 2012, p.62) 
Para coletar estes dados, utilizei o modelo de entrevista qualitativa sem-aberta, com questões semiestruturadas. Para esta conversa, foi necessária a composição de um roteiro que possibilitava novas abordagens a fim de coletar ao máximo a percepção dos colaboradores com relação ao assunto proposto, ou seja, a partir disso, "cada questão é aprofundada a partir da resposta do entrevistado, como um funil, no qual perguntas gerais vão dando origem a específicas" (DUARTE e BARROS, 2012, p. 66).

Existem cinco classificações para os respondentes referentes a entrevista em profundidade, que são: o especialista, o informante-chave, o informante-padrão, informante complementar e o informante extremista (DUARTE e BARROS, 2012). O perfil que mais se adequava a esta pesquisa acadêmica foi o informante-padrão. Neste caso, uma "fonte envolvida com o tema, mas que pode ser substituída por outra sem que se espere prejuízo na qualidade das informações obtidas" (DUARTE e BARROS, 2012, p.70). Ainda que a participação dos colaboradores fosse mais do que essencial neste projeto, não havia um perfil específico a ser convidado, pois a mudança dos entrevistados não interferia no resultado final.

Este formato de entrevista "não permite testar hipóteses, dar tratamento estatístico às informações, definir a amplitude ou quantidade de um fenômeno" (DUARTE e BARROS, 2012, p.63). Por isso, este trabalho não tem o objetivo de definir ou apontar correções na forma como a estratégia tem sido posta em prática, mas sim analisar a percepção dos colaboradores ao serem inseridos como pauta no jornal Grand News.

\section{Referencial teórico}

"O conceito de cultura foi estabelecido no final do século XVIII para designar a gestão do pensamento e do comportamento humano" (BAUMAN apud TOMEI, 2008, p.19). Nesse contexto, Lotman define a cultura como uma "rede de signos e significados que expressam e ocultam as intricadas relações corporativas" (LOTMAN apud CURVELLO, 2012, p.43).

Outro conceito importante a definir, antes de nos aprofundarmos no tema central deste capítulo, é a organização. Nesse quadro, Motta apud Kunsch (2003) afirma que "organização significa estudar órgãos e sobre eles agir, isto é, sobre as empresas, instituições e os empreendimentos humanos, com o fim de torná-los mais eficazes e eficientes (MOTTA apud KUNSCH, 2003, p.24). 
A partir do entendimento dos conceitos de cultura e organização, avançamos para o referencial teórico base deste capítulo. Schein apud Tomei (2008) aponta o conceito de cultura organizacional como:

Um padrão de pressupostos básicos compartilhados que um grupo aprendeu ao resolver seus problemas de adaptação externa e integração interna e que funcionou bem o suficiente para serem considerados válidos e ensinados a novos membros como a forma correta de perceber, pensar e sentir com relação a esses problemas (SCHEIN apud TOMEI, 2008, p.21).

Para ele, a cultura de uma organização pode ser identificada pela linguagem utilizada nos meios, as narrativas e rituais de passagem, além dos hábitos e valores que são transmitidos por uma determinada organização (SCHEIN apud TOMEI, 2008).

Os sistemas internos da organização podem ser identificados pelo departamento de Recursos Humanos, Marketing, Finanças, entre outros (MOTTA; VASCONCELOS, 2006). O objetivo é que cada sistema trabalhe suas funções de maneira conjunta, ou seja, integrada a todas as partes da empresa, a fim de manter o equilíbrio interno da organização (MOTTA e VASCONCELOS, 2006).

Curvello (2012) afirma, que na organização a cultura não é dada apenas pelo discurso oficial transmitido pelos líderes, mas também é composta pela experiência tida pelo grupo o que torna esses conceitos internos práticas valorizadas (CURVELLO, 2012). Tomei (2008) fala ainda que, "à medida que os conceitos e soluções funcionam bem para o grupo, esses são valorizados, até chegarem ao ponto de se tornarem inquestionáveis" (TOMEI, 2008, p.21).

Antes de falarmos especificamente sobre a comunicação interna, é precisa deixar claro, a diferença entre este formato, que tem como público-alvo os colaboradores da organização, da comunicação organizacional, que tem como público-alvo todos aqueles a quem a organização se direciona, como por exemplo: clientes, colaboradores, fornecedores, etc (CURVELLO, 2012). A comunicação organizacional é estabelecida como todo o conjunto das atividades comunicacionais que se aplicam a todos os tipos de organização, sejam elas, públicas, privadas, sem fins lucrativos. Ou seja, esta não se restringe ao que se qualifica somente "empresa" (KUNSCH, 2003). Desta forma, a comunicação organizacional abarca todas as atividades que se referem a comunicação institucional, comunicação mercadológica, comunicação interna e comunicação administrativa (KUNSCH, 2003). 
A partir desse pressuposto, podemos nos ater ao conceito que dará embasamento ao tema deste capítulo, que é a Comunicação interna no âmbito das organizações. Para Kunsch (2003), "ela seria um setor planejado, com objetivos bem definidos, para viabilizar toda a interação possível entre a organização e seus empregados, usando ferramentas da comunicação institucional e até da comunicação mercadológica" (KUNSCH, 2003, p.154). O objetivo deste segmento é estimular a troca de informações e experiências entre os colaboradores e a organização, a fim de obter participação em todos os níveis hierárquicos da empresa (RHODIA apud KUNSCH, 2003).

Segundo Kunsch (2003), a comunicação interna precisa fazer parte da estratégia da empresa e a sua integração na política da companhia tem reflexos positivos na propagação da cultura organizacional ao público interno. Ela sustenta que dentro desse quadro, seria possível conciliar "os interesses dos empregados com os da organização" (KUNSCH, 2003, p.157).

O processo comunicacional dentro das organizações é estipulado por meio de fluxos. São estes: fluxo ascendente, normalmente dado por sugestões e críticas dos colaboradores; fluxo horizontal, geralmente dado pelos setores no cotidiano da organização; fluxo transversal, que permite a transmissão de mensagens entre diferentes departamentos; e fluxo descendente, que é quando as informações têm origem nos cargos de liderança e são transmitidos por meio de boletins e jornais de empresa, mais conhecido como house organ. Na comunicação empresarial, este último formato de fluxo das informações é o que normalmente predomina (CURVELLO, 2012). Esta ferramenta de comunicação tem a função de noticiar fatos importantes dentro do período de veiculação deste material. Geralmente, tem como característica um formato com matérias informativas curtas e no estilo revista. Dependendo do tamanho da organização, além das matérias também são acrescentados artigos de opinião que tenham relevância para a cultura organizacional da empresa (PALMERSTON, 2012).

Para falar sobre o jornal será necessário compreender alguns conceitos oriundos da comunicação. É importante entender o processo de estruturação de uma pauta até que ela se torne notícia e seja transmitida à comunidade pelo veículo de comunicação. Primeiramente vamos nos aprofundar no conceito de pauta. Neiva (2013) define este conceito como uma "preparação de matéria jornalística já programada, indicação dos detalhes a serem abordados sobre determinado assunto e do modo de focalizá-lo" (NEIVA, 2013, p.428). Nesse mesmo contexto, Rabaça e Barbosa (2014) definem este conceito como um "relato de fatos atuais, de interesse e importância para a comunidade, e capaz de ser compreendido pelo público (RABAÇA e BABORSA, 2014, p.190). Para que um fato se torne notícia, ele precisa seguir três critérios básicos de noticiabilidade que são: relevância, interesse e utilidade da notícia (NEIVA, 
2013). São esses pontos que irão definir se o fato poderá ser comunicado pelos diversos veículos. O objetivo da notícia deve ser o de proporcionar aos cidadãos que "participem do debate que forma a esfera pública" (NEIVA, 2013, p. 401).

Como já explicado anteriormente, o house organ tem a função de veículo de comunicação de uma organização, o que pode ser tido pelo jornal da empresa (NEIVA, 2013). Os jornais internos além de compor as mensagens do presidente da organização e as principais ações que serão realizadas, também podem conter colunas que abordam temas não tão centralizados aos assuntos da companhia.

\section{A Organização}

A organização Hyatt foi fundada no ano de 1957, na cidade de Los Angeles, nos Estados Unidos, pelo empresário Jay Pritzker. Ainda pequena, naquele ano ainda não era uma organização global, mas sim um motel anexo ao aeroporto da cidade. No ano de 1962, a empresa passou a ser pública, e na década seguinte expandiu o seu negócio a outras cidades americanas. Após alguns anos, a empresa passou por uma separação enquanto organização, mas em 2004 voltou a ser uma entidade única e que hoje detém diversas marcas no seu portfólio.

\section{A American Marketing Association define marca como "uma experiência do cliente} representada por um conjunto de imagens e ideias; frequentemente refere-se a um símbolo, tal como um nome, logotipo, slogan, e esquema de design"2.

Por conta do jonal interno Grand News ser o objeto de estudo desta pesquisa, vou delimitar a minha análise com base nesse perfil. Visto isso, a partir daqui será realizado o aprofundamento das características da marca Grand e do hotel Grand Hyatt Rio de Janeiro.

O hotel Grand Hyatt Rio de Janeiro se apresenta com a proposta de ser o primeiro resort urbano da região da Barra da Tijuca, que fica na Zona Oeste da cidade. Sua abertura foi realizada em março do ano de 2016. O resort é um "hotel com infraestrutura de lazer e entretenimento que disponha de serviços de estética, atividades físicas, recreação e convívio com a natureza no próprio empreendimento"3.

\footnotetext{
2 Definição disponível no dicionário da American Marketing Association. <Acesso em 04/07/2019>

${ }^{3}$ Definição disponível no Sistema Brasileiro de Classificação de Meios de Hospedagem do Ministério do Turismo.

$<$ Acesso em 04/07/2019>
} 
Para manter essa rede de serviços, o hotel dispõe de cerca de 400 colaboradores, diretos e/ou terceirizados. O total de colaboradores diretos até o momento desta pesquisa era de 330 pessoas. Como este artigo acadêmico tem como objeto um veículo de comunicação interna, não é do interesse deste trabalho se aprofundar nas relações da marca com o seu público externo.

A estrutura de governança corporativa do hotel se divide da seguinte maneira: um Gerente Geral e mais quatro diretores para as áreas de Finanças, Vendas e Marketing, Experiência do Cliente e Experiência do Colaborador.

A organização deve ser vista como um organismo vivo, no qual todos têm acesso a recursos físicos como os espaços e materiais de trabalho, o que lhes permite a continuidade da prestação dos serviços conforme a atividade proposta (FARIAS e LOPES, 2016), neste caso a hospitalidade. No entanto, é preciso considerar "a empresa também como uma comunidade de pessoas" (FARIAS e LOPES, 2013, p.49). Alguns elementos intangíveis são fundamentais para essa relação funcionar. O Grand Hyatt Rio de Janeiro tem como base para o seu negócio o mesmo propósito da organização: "Cuidamos das pessoas para que elas sejam o seu melhor ${ }^{4 "}$, e que pode ser considerado um elemento intangível desta companhia.

No Grand Hyatt Rio de Janeiro, a Comunicação interna faz parte da estratégia da área da Experiência do Colaborador e também dá suporte aos demais departamentos no que consiste a comunicação e produção de eventos internos. Atualmente, esta área segue um planejamento feito com base na convergência de mídias. Este conceito é definido por Rabaça e Barbosa (2014) como a "integração dos diversos meios de comunicação. Uso de diferentes veículos como porta de entrada para a mesma base de conteúdos (RABAÇA e BARBOSA, 2014 , p.58). A estratégia de convergência de mídia foi implementada por conta da variedade de veículos de comunicação interna que o hotel dispõe. Entre os meios utilizados estão: o jornal Grand News, Grupo ExtraordináRIO no Facebook, WhatsApp Corporativo, TV Corporativa, displays do restaurante dos colaboradores, quadro "Curtinhas", murais internos e o e-mail da Comunicação interna. O objetivo é que cada veículo contribua para comunicação do mesmo conteúdo, mas sob uma vertente específica. Dessa forma trazemos formatos diferentes de um mesmo conteúdo, o que colabora para que os colaboradores estejam informados sobre o que está sendo planejado ou o que foi realizado no hotel.

\footnotetext{
${ }^{4}$ Propósito da Hyatt disponível no site oficial da organização. <Acesso em 04/07/2019>
} 


\section{Análise do objeto}

O método de pesquisa utilizada para a análise do jornal interno foi a entrevista em profundidade (DUARTE e BARROS, 2012). Para esse processo foi utilizado um modelo de roteiro com questões semiestruturadas (DUARTE e BARROS, 2012). O método de escolha dos entrevistados seguiu o modelo de reconhecimento dos colaboradores realizado pelo hotel.

O programa Hystar é um modelo utilizado em toda a organização e que reconhece os colaboradores que mais se destacaram durante o trimestre. Ao longo do ano são realizadas quatro edições e após as edições trimestrais, é realizada a edição anual. O método de premiação pode variar de hotel para hotel, no entanto o programa é uma prática da organização como um todo. O programa de reconhecimento do Grand Hyatt Rio de Janeiro tem um formato que passa por todas as áreas do hotel e permite o mesmo destaque dos colaboradores entre as categorias estabelecidas.

Nesse sentido a organização busca promover a sua estratégia seus objetivos por meio de cerimônias e ritos de passagem. Os colaboradores são estimulados a adotar práticas e comportamentos que fazem parte da cultura organizacional da companhia, por meio de premiações e reconhecimentos (MOTTA e VASCONCELOS, 2013).

O Grand News é o principal veículo de comunicação interna do hotel. Com a periodicidade de duas edições por mês (todo o dia $1^{0}$ e 15 de cada mês), o jornal interno promove a cultura organizacional da empresa. Por meio dele são anunciadas as principais mensagens do Gerente Geral, atividades e informações referentes ao departamento de Recursos Humanos, mudanças e planejamento estratégico da Hyatt, colunas de bem-estar assinadas pelos próprios colaboradores, atividades do programa Hyatt Thrive (Responsabilidade Social Corporativa), entre outros assuntos.

Sua divulgação é realizada por diversos meios de comunicação interna do hotel e segue a estratégia de convergência de mídia que é base para o planejamento da comunicação interna. As tiragens impressas do jornal são expostas nos murais. O jornal também é enviado por email aos colaboradores da filial do hotel nas cidades do Rio de Janeiro e São Paulo, que também compartilha o jornal. Além disso, a edição online é postada no WhatsApp Corporativo e também no grupo ExtraordináRIO (Facebook). A TV Corporativa realiza chamadas curtas e é utilizada como meio para divulgar os temas abordados na edição que está disponível no mural ou nos meios digitais. 
O jornal teve a sua primeira edição lançada no primeiro mês de operação do hotel (março/2016). Seguindo um design simples e ainda com uma estrutura de informativo, o objetivo neste momento era informar as principais ações referentes aos treinamentos e suporte dado pelo departamento da Experiência do Colaborador aos novos funcionários com relação aos benefícios trabalhistas.

A partir da análise realizada com os entrevistados, é possível identificar que nenhum deles tem uma memória assertiva com relação ao conteúdo do jornal, apenas afirmam que o jornal apresentava informações mais concisas e temas com pouco aprofundamento: "(...) ele parecia ser mais incompleto antigamente e tinha menos informação com certeza, até pelo hotel ser novo"5.

Cerca de quatro meses depois da primeira edição, o departamento de Treinamento e Desenvolvimento criou uma vaga de estágio especializada para a função de Comunicação interna, e partir disso, o jornal passa a ter uma nova estrutura com pautas e organização gráfica pensadas para chamar a atenção dos colaboradores e obter um maior alcance no que diz respeito a rotina do hotel.

Nesse novo formato, o nome do jornal ganha um logotipo que utiliza a cor da marca Grand Hyatt e passa veicular uma mensagem assinada pelo Gerente Geral a todos os colaboradores. Os assuntos e temas são trabalhados com destaque, por meio de cores chamativas e uma diagramação menos formal. Entre as pautas do jornal estão as confraternizações realizadas no restaurante dos colaboradores, os eventos realizados pelo departamento de Marketing, os treinamentos realizados e as novas contratações e promoções do hotel.

O jornal passa a partir disso a colocar o colaborador mais envolvido nos assuntos relacionados a rotina da empresa de uma forma mais local. Nesse novo formato, o Grand News passa a ter um caráter didático para apresentar aos colaboradores o que são e como são realizadas as atividades internas da empresa. Ainda nesse período, o jornal era veiculado somente por e-mail e nos murais do hotel.

Com base nas entrevistas é possível identificar que essa mudança foi logo observada. O jornal deixa de ter um caráter de informativo e passar a ter um formato mais atraente. As pautas sobre as atividades realizadas no hotel começam a chamar a atenção dos colaboradores o que pressupõe um alcance maior dos leitores.

${ }^{5}$ Entrevista concedida por VIEIRA, Juliana. Entrevista 2. [Jul. 2019]. Entrevistador: Vinícius Rodrigues M. Silva. Rio de Janeiro, 2019. 
No ano de 2017, há a mudança do estagiário responsável pela Comunicação interna e o jornal passa por um novo processo de estruturação. O Grand News passa a adotar na sua grade fixa de pautas colunas com temas referentes a saúde e bem-estar. Esse é o primeiro passo para uma participação mais ativa dos colaboradores. As colunas são assinadas pela professora de Educação Física do Atiaia Spa \& Fitness Zayra Mendes e pela nutricionista Roberta Barbieri. Além disso, pautas sobre os comitês de eventos internos e também sobre dicas de produtos feitos no hotel também começam a ser explorados.

A maioria dos entrevistados sugere que as colunas sobre bem-estar e saúde são temas de grande interesse entre os entrevistados. Esses temas são dados como úteis para o dia-a-dia fora do hotel, pois muitas das dicas têm como referência a alimentação saudável e a prática de exercícios físicos.

Um deles diz estar atento a todas as informações referente a coluna da professora de Educação Física do hotel e aponta que nesse aspecto o jornal tem muita utilidade.

Acho que estou chegando em uma idade que eu preciso me cuidar fisicamente e, principalmente, no quesito saúde. Então venho me policiando até para frequentar academia, para ficar mais próximo de um estilo de vida mais saudável mais equilibrado. Então, eu diria que sim. É aplicável e já fiz uso de reportagens focadas em qualidade de vida e exercícios ${ }^{6}$.

Já no ano de 2018, o jornal toma um formato que apresenta mais de perto a rotina do colaborador dentro da empresa e torna ele personagem principal nas pautas do jornal, com relatos pessoais de trajetória profissional, visita das famílias nos eventos internos do hotel e promoção das atividades de desenvolvimento profissional interno. Nesse momento, o jornal já era compartilhado por meio do grupo ExtraordináRIO (Facebook).

Após o processo de reestruturação das pautas do jornal, foi percebido também uma necessidade de divulgar com mais clareza e de maneira mais assertiva os temas referentes ao jornal. Com base nas entrevistas, é possível afirmar que o aumento das opções de veículos de comunicação se tornou uma oportunidade de obter um maior alcance dos assuntos que os colaboradores mais tinham interesse em saber.

As entrevistas apresentam que em sua maioria a leitura do jornal é realizado por meio do celular. É concebível afirmar a partir disso, que compartilhar o Grand News pelo grupo

\footnotetext{
${ }^{6}$ Entrevista concedida por BANDINI, Eduardo. Entrevista 7. [Jul. 2019]. Entrevistador: Vinícius Rodrigues M. Silva. Rio de Janeiro, 2019.
} 
ExtraordináRIO e também no HyattZap tornou esse processo de leitura mais fácil, pois o colaborador não precisa necessariamente estar no ambiente de trabalho para consumir este conteúdo.

Hoje qualquer colaborador do hotel consegue ter acesso ao jornal de forma simples e clara, seja pelo WhatsApp ou Facebook, no caso para quem não tem e-mail, pois nem todos os colaboradores tem acesso a essa ferramenta?.

Meu telefone apita quando chega alguma coisa. Então eu já deixei ele programado para quando chegar alguma coisa no computador. Ele apita, eu vejo que é o grupo ExtraordináRIO, eu vou lá e clico $^{8}$.

Segundo Kunsch, é necessário criar novos meio de interação com o colaborador. Isso se dá por meio da coordenação de mídias audiovisuais e interativas que apresentem as atividades realizadas pela empresa, além de promover ações que estimulem a participação, a integração e o interesse do colaborador na companhia. É preciso tornar a organização um coparticipante ativo na vida do funcionário ( $\mathrm{KUNSCH}, 2003$ ).

Outro ponto importante está na antecipação às crises por meio de assuntos que para alguns colaboradores possam ser delicados. Por exemplo, foi citada por uma das entrevistadas a alteração do plano de saúde e como a reportagem foi fundamental para que dúvidas e/ou ruídos fossem esclarecidos. Como citado por Kunsch (2003), a comunicação interna é uma ferramenta que pode auxiliar na resposta dos colaboradores de maneira antecipada, o que favorece planejar soluções em curto prazo.

Com base nas entrevistas foi possível identificar as palavras mais utilizadas para definir o Grand News. Segundo os entrevistados, o jornal é dinâmico, completo, universal, informativo e acessível.

\section{Considerações finais}

A partir do tema analisado e com base nas entrevistas realizadas, podemos deduzir que a comunicação interna do hotel Grand Hyatt Rio de Janeiro tem uma função estratégica bem definida no que diz respeito aos colaboradores. Como já citado por Schein (apud TOMEI,

\footnotetext{
7 Entrevista concedida por IOTI, Thiago. Entrevista 6. [Jul. 2019]. Entrevistador: Vinícius Rodrigues M. Silva. Rio de Janeiro, 2019.

${ }^{8}$ Entrevista concedida por FREITAS, Maria Vitória de. Entrevista 3. [Jul. 2019]. Entrevistador: Vinícius Rodrigues

M. Silva. Rio de Janeiro, 2019.
} 
2008), por meio da relação com a cultura organizacional, os colaboradores compartilham um padrão de pressupostos que atende a este grupo e funciona aos novos membros como forma de pensar e sentir dentro do ambiente da companhia.

A organização funciona como um organismo vivo por meio da colaboração dos diferentes departamentos. O propósito da companhia é dado com ponto de partida para as ações de uma maneira geral. "Cuidamos das pessoas para que elas possam ser o seu melhor", se torna uma cultura que não pode ser separada da organização, pois ao mesmo tempo que ela é transmitida pelo discurso oficial dos líderes, ela também é vivenciada pelos colaboradores de uma maneira geral.

Outro ponto que podemos deduzir é que o jornal interno hoje é concebido por pautas que transitam entre fluxos descendentes, que são aqueles assuntos cujas informações são direcionadas pela liderança (CURVELLO, 2012), e fluxos transversais, que são assuntos que permitem a troca de mensagens entre funcionários de diferentes departamentos (CURVELLO, 2012).

Essa percepção pode ser identificada quando o Grand News passa a veicular tanto mensagens estratégicas e que determinam a rotina do hotel, quanto reportagens sobre a história dos colaboradores e também colunas assinadas pelos próprios, com assuntos que fazem não tem impacto direto na rotina do hotel.

Por meio das entrevistas deduzimos que os colaboradores têm apreço por estes assuntos que fazem reflexões motivacionais para a sua própria rede de influência, no entanto não fica claro para eles de que maneira e porque essas pautas são definidas. Dois entrevistados apresentam essa dúvida e sugerem inclusive uma aproximação maior do jornal com os colaboradores por meio de sugestão de pautas e até mesmo uma apuração mais precisa sobre os impactos positivos trazidos pela função realizada por eles dentro da organização.

Um ponto que podemos inferir como positivo, a partir dessa análise é a percepção da acessibilidade das edições do jornal. Em sua maioria, os entrevistados apontaram a facilidade de acesso às informações do jornal por meio do celular e também e-mail da companhia. 0 que pode ser concebido com uma estratégia positiva para a comunicação interna do hotel.

Como já apresentado no início desta pesquisa, o objetivo não é definir ou apontar correções na estratégia de comunicação interna do hotel, mas a partir dessa análise é possível colher 
sugestões para atender a algumas demandas do próprio leitor com base nas entrevistas realizadas.

Por último, podemos perceber que a cultura organizacional da organização está sendo transmitida de maneira concisa. A análise das palavras que os entrevistados utilizaram para definir o jornal sugere um diálogo entre o propósito e valores da empresa com os leitores do Grand News. Dentro desse contexto, seria possível conciliar os interesses dos colaboradores com os do hotel Grand Hyatt Rio de Janeiro.

\section{Referências bibliográficas}

\subsection{Livros e artigos}

CURVELLO, João José Azevedo. Comunicação interna e cultura organizacional. Brasília: Casa das Musas, 2012.

DUARTE, Jorge; BARROS, Antônio. Métodos e técnicas de Pesquisa em Comunicação. São Paulo: Editora Atlas, 2012.

FARIAS, Luiz Alberto; LOPES, Valéria de Siqueira Castro. Comunicação, Governança e Organizações. Porto Alegre: Editora PUCRS, 2016.

KUNSCH, Margarida Maria Krohling. Planejamento de relações públicas na

Comunicação Integrada. São Paulo: Summus, 2003.

MOTTA, Fernando C. Prestes e VASCONCELOS, Isabella F. Gouveia. Teoria Geral da Administração. São Paulo: Cengage Learning, 2013.

NEIVA, Eduardo. Dicionário Houaiss de Comunicação e Mídia. São Paulo: PubliFolha, 2013.

PALMERSTON, Virgínia Borges. O Discurso Organizacional no House Organ: gêneros, imaginários e ethos como estratégias de construção da identidade e da credibilidade das organizações. Tese de Doutorado apresentada à Universidade Federal de Minas Gerais, Faculdade de Letras. Programa de Pós-Graduação em Letras, Belo Horizonte, 2012.

RABAÇA, Carlos Alberto; BARBOSA, Gustavo Guimarães. Dicionário essencial de Comunicação. Rio de Janeiro: Lexikon, 2014.

TOMEI, Patricia Amélia. Cultura e Mudança organizacional. Rio de Janeiro: Editora PUCRio, 2008. 


\subsection{Sites}

AMERICAN MARKETING ASSOCIATION

https://www.ama.org/ <Acessado em 04/07/2019>

HYATT

https://www.hyatt.com/ <Acessado em 04/07/2019>

SISTEMA BRASILEIRO DE CLASSIFICAÇÃO DE MEIOS DE HOSPEDAGEM

http://www.classificacao.turismo.gov.br/ <Acessado em 04/07/2019> 